\title{
Perancangan Alat Ukur Kadar Alkohol Berbasis Mikrokontroler Dengan Metode Fuzzy Tsukamoto
}

\author{
Mario Antoniya Setiawan, David, Gat \\ Teknik Informatika \\ Sekolah Tinggi Manajemen Informatika dan Komputer Pontianak \\ Jalan Merdeka No. 372 Pontianak, Kalimantan Barat \\ Telp (0561) 735555, Fax (0561) 737777 \\ e-mail: marioantoniya.zhong@gmail.com, DavidLiauw@gmail.com, \\ gutsy1802@gmail.com
}

\begin{abstract}
Abstrak
Alat ukur kadar alkohol merupakan salah satu alat bantu yang sangat dibutuhkan sinshe patah tulang dalam setiap prakteknya. Permasalahan yang sering terjadi adalah tidak adanya pengukuran kadar alkohol khususnya arak putih. Nilai kadar alkohol diketahui dari kepercayaan mulut sang penjual saja. Pada penelitian ini, penulis menggunakan metode Riset Eksperimental disertai juga dengan teknik pengumpulan data yang digunakan adalah pengumpulan data primer dan sekunder, yaitu dengan studi literatur, dokumentasi, dan observasi. Pemodelan perangkat yang digunakan adalah Unified Modeling Language (UML). Metode analisis dan perancangan sistem menggunakan metode Waterfall dengan Metode Fuzzy Tsukamoto. Penelitian ini menghasilkan sebuah perangkat lunak alat ukur kadar alkohol berbasis mikrokontroler Arduino UNO. Bahasa pemrograman yang digunakan dalam membangun software adalah Arduino IDE yang dasarnya adalah bahasa $C$ dan Visual Basic 6.0. Hasil dari penelitian ini adalah perangkat lunak mampu mengukur alkohol dan menampilkan output hasil yang dapat membantu dan mempermudah sinshe dalam mengobati pasien patah tulang.
\end{abstract}

Kata kunci : Arduino UNO, Fuzzy Tsukamoto, Unified Modeling Language, Visual Basic 6.0 .

\section{Abstracts}

Alcohol meter is one of the most needed tools for sinshe (traditional bone specialist). The problem that often happens is absence of alcohol meter. The percentage of alcohol is only known from the sellers. In this research, the authors use the method of Experimental Research accompanied also by the data collection techniques used are primary and secondary data collection, which is literature study, documentation, and observation. Modeling device used is Unified Modeling Language (UML). Method of analysis and system design using Waterfall method with Fuzzy Tsukamoto Method.The purpose of this research is to build an alcohol meter software Arduino UNO-based. Programming language that used in this research is Arduino $I D E$ which is essentially a $C$ language and Visual Basic 6.0. The result of this research is a software that able to measure alcohol percentage and display output results that can help sinshe in treating patients.

Keywords : Arduino UNO, Fuzzy Tsukamoto, Unified Modeling Language, Visual Basic 6.0.

\section{PENDAHULUAN}

Alkohol dewasa ini telah banyak beredar di pasaran dikehidupan sehari-hari. Penggunaan etanol atau yang lebih dikenal dengan alkohol biasanya dicampurkan ke dalam 
berbagai jenis minuman dan juga dicampurkan kedalam produk obat-obatan. Munculnya para produsen nakal yang membuat campuran minuman/cairan dengan kadar alkohol yang melewati batas aturan kadar alkohol yang telah ditentukan Departemen Kesehatan (DEPKES) dan Badan Pengawasan Obat dan Makanan (BPOM) telah menjadi salah satu permasalahan yang cukup serius.

Sinshe (ahli/guru) patah tulang masih dikategorikan kedalam dukun keseleo maupun patah tulang dikarenakan cara pengobatannya yang tradisional walaupun ada juga yang sudah menerapkan sedikit ilmu kedokteran di dalam metode pengobatannya. Sinshe patah tulang menggunakan alkohol yang lebih sering disebut dengan arak putih dalam proses pengobatan pasien keseleo ataupun patah tulang kemudian diramu dan dicampurkan dengan obat racikan tradisional dan dikompreskan atau ditempelkan pada daerah yang keseleo maupun patah tulang.

Sulitnya sinshe patah tulang dalam mengukur kadar alkohol yang harus dicampurkan ke obat keseleo atau patah tulang karena kadar alkohol yang tinggi akan berbahaya untuk kulit pasien, inilah yang menjadi alasan untuk melatarbelakangi penulis dalam menulis penelitian kali ini. Kadar alkohol pada arak putih yang dihasilkan oleh para pengrajin arak putih adalah sekitar $30 \%-40 \%$. Sedangkan alkohol dengan kadar 70\%-90\% adalah pelarut untuk membersihkan zatzat tertentu dan bersifat antiseptik (membunuh kuman) serta sangat beracun bila dikonsumsi oleh manusia. Cara pengukuran yang dilakukan oleh sinshe masih dilakukan dengan cara konvensional, yaitu dengan melakukan campuran air dan alkohol dengan perbandingan yang diinginkan. Kadar alkohol yang dapat diterima kulit badan dalam waktu yang berkepanjangan adalah kisaran $15 \%-25 \%$.

Untuk menentukan kadar alkohol pada sampel dari cairan yang beralkohol diperlukan uji laboratorium yang prosesnya cukup lama dan menggunakan peralatan laboratorium yang cukup mahal. Oleh sebab itu perlu dilakukan penelitian untuk mengukur kadar etanol pada minuman maupun cairan dengan waktu yang relatif singkat dan menunjukkan hasil yang mendekati akurat dengan menggunakan mikrokontroler Arduino karena uji sampel yang memakan waktu lama tidak terlalu efektif.

Alat ukur yang peneliti rancang adalah alat ukur kadar alkohol jenis etanol yang menggunakan Arduino UNO sebagai pusat pengontrolan. Perangkat lunak (software) dirancang menggunakan Visual Basic 6.0 yang menampilkan apakah alkohol layak digunakan untuk pengobatan atau tidak. Logika fuzzy ditanamkan kedalam otak mikrokontroler Arduino dengan menggunakan USB Downloader yang dibantu oleh software Arduino IDE dan data yang didapat dari perhitungan dikirim menggunakan kabel USB Downloader lagi ke Visual Basic 6.0. Bahasa pemrograman yang digunakan pada Arduino UNO ini adalah Bahasa C. Pada alat ukur kadar alkohol ini, input berasal dari sensor alkohol yang didekatkan pada cairan etanol, kemudian terjadilah proses perhitungan oleh prosesor mikrokontroler. Setelah itu, output berupa hasil persentase alkohol di tampilkan pada aplikasi yang telah dirancang menggunakan Visual Basic 6.0 dan ditampilkan juga pada Liquid Crystal Display (LCD) berukuran 16x2.

\section{METODE PENELITIAN}

Pada penelitian ini, penulis menggunakan metode Riset Eksperimental disertai juga dengan teknik pengumpulan data yang digunakan adalah pengumpulan data primer dan sekunder, yaitu dengan studi literatur, dokumentasi, dan observasi. Pemodelan perangkat yang digunakan adalah Unified Modeling Language (UML). Metode analisis dan perancangan sistem menggunakan metode Waterfall dengan Metode Fuzzy Tsukamoto. Penelitian ini menghasilkan sebuah perangkat lunak alat ukur kadar alkohol berbasis mikrokontroler Arduino UNO. Bahasa pemrograman yang digunakan dalam membangun software adalah Arduino IDE yang dasarnya adalah bahasa $\mathrm{C}$ dan Visual Basic 6.0. Proses pengujian pada penelitian ini menggunakan metode pengujian Black Box. Hasil dari penelitian ini adalah perangkat lunak mampu mengukur 
alkohol dan menampilkan output hasil yang dapat membantu dan mempermudah sinshe dalam mengobati pasien patah tulang

\section{HASIL PENELITIAN DAN PEMBAHASAN}

Penelitian yang penulis lakukan dalam perancangan alat ukur kadar alkohol berbasis mikrokontroler ini menggunakan metode Waterfall. Metode Waterfall merupakan salah satu metode pengembangan perangkat lunak yang klasik namun bersifat sistematis. Tahapan pada metode Waterfall diantaranya adalah analysis, design, implementation, dan maintenance. Pada penelitian ini, penulis mengurutkannya dengan tahapan berikut, diantaranya adalah arsitektur perangkat lunak, perancangan algoritma alat ukur, pengujian alat ukur, dan pengujian jarak sensor.

\subsection{ARSITEKTUR PERANGKAT LUNAK}

Tahap analisys dimulai dengan Arsitektur perangkat lunak berguna untuk memudahkan pemahaman tentang sistem perangkat lunak yang akan dibangun. Arsitektur perangkat lunak perancangan alat ukur kadar alkohol ini adalah sebagai berikut :

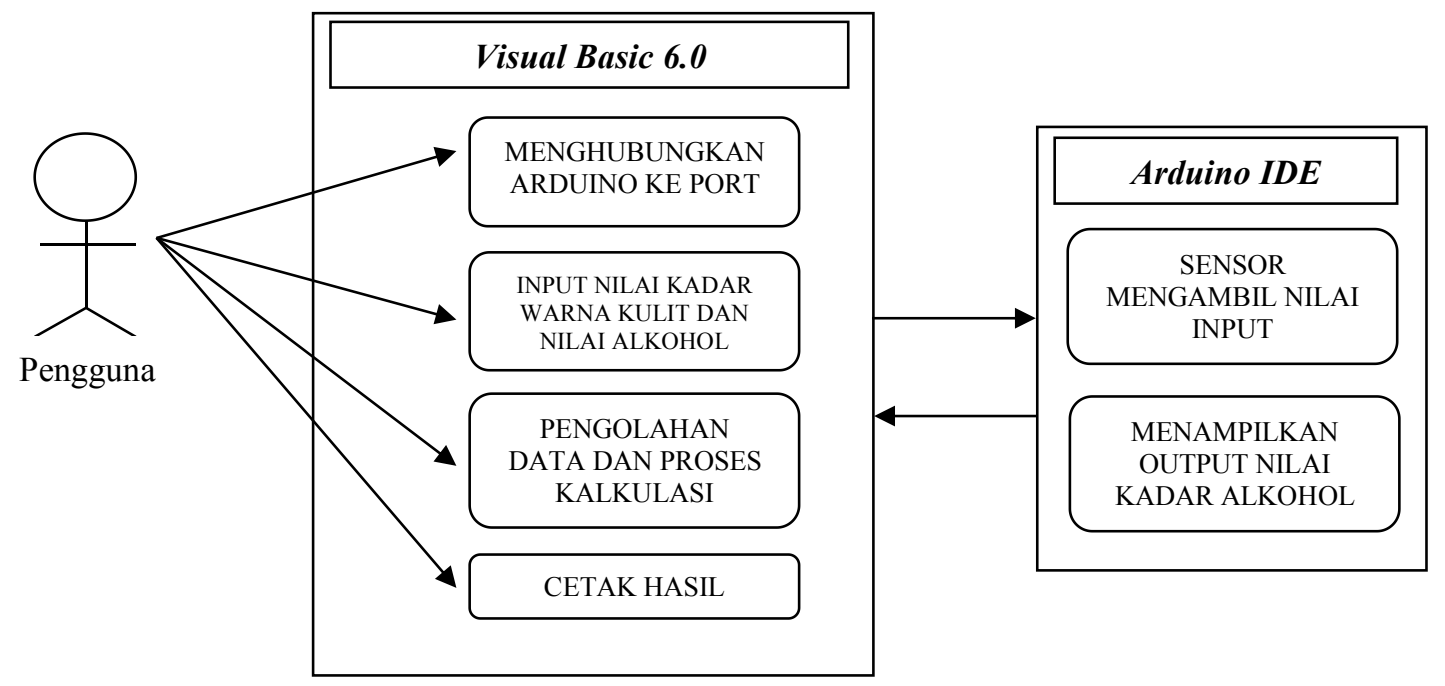

Gambar 3.1 Arsitektur Perangkat Lunak Alat Ukur Kadar Alkohol

\subsection{PERANCANGAN ALGORITMA ALAT UKUR}

Perancangan algoritma aplikasi alat ukur alkohol yang hendak dihasilkan dalam penelitian ini menggunakan bagan alir atau flowchart. Algoritma yang dirancang berupa algoritma proses perhitungan pada Fuzzy Tsukamoto. Berikut ini adalah bagan alir dari algoritma alat ukur kadar alkohol : 


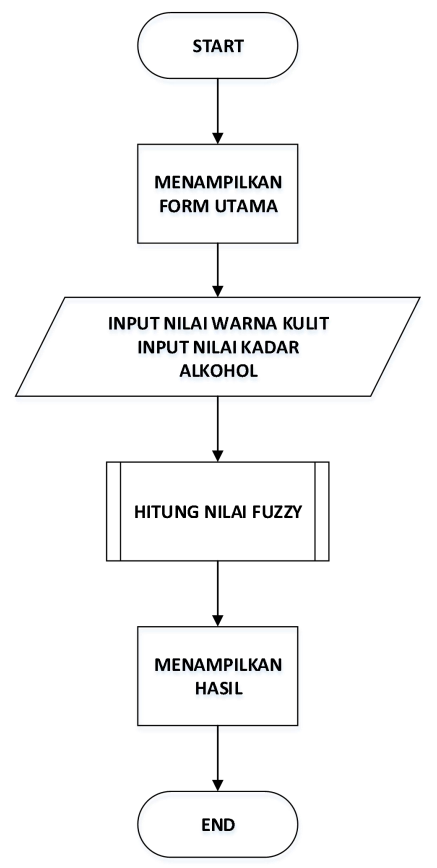

Gambar 3.2 Perancangan Algoritma Alat Ukur Kadar Alkohol

\subsection{PENGUJIAN ALAT UKUR}

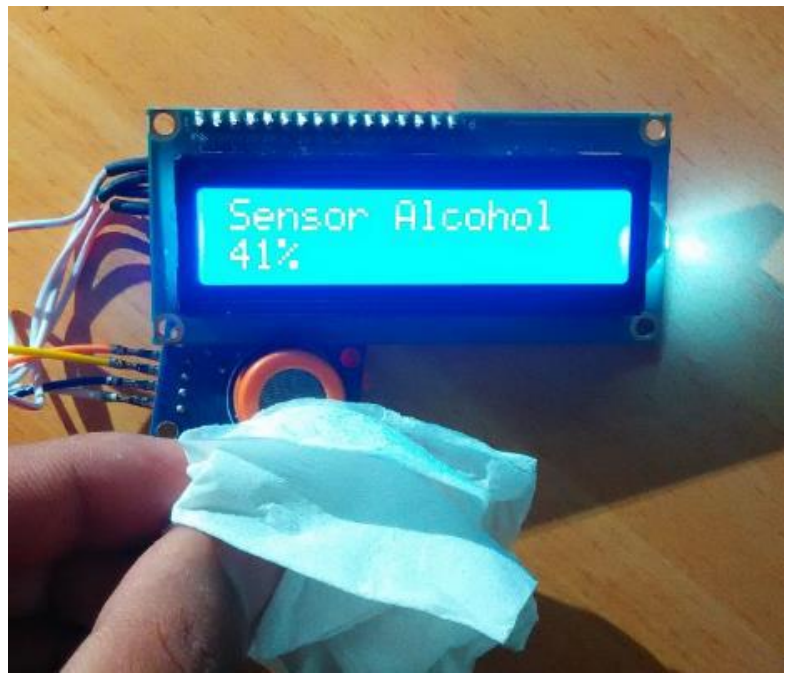

Gambar 3.3 Pengujian pada sensor MQ-3 dan LCD 16x2

Berikut adalah hasil pengujian White Box pada Arduino UNO. Alat ukur bekerja dengan baik sesuai dengan sistem yang dirancang oleh penulis. Setiap Arduino mendapat catu daya / daya listrik, Arduino mengkalibrasi sensor MQ-3, agar komponen $\mathrm{SnO}_{2}$ pada sensor dipanaskan dan siap digunakan. Nilai sensor berubah setiap 1 detik yang berarti nilai alkohol didapatkan secara Real Time.

Berikutnya adalah pengujian aplikasi perangkat lunak yang sudah dirancang oleh penulis. 


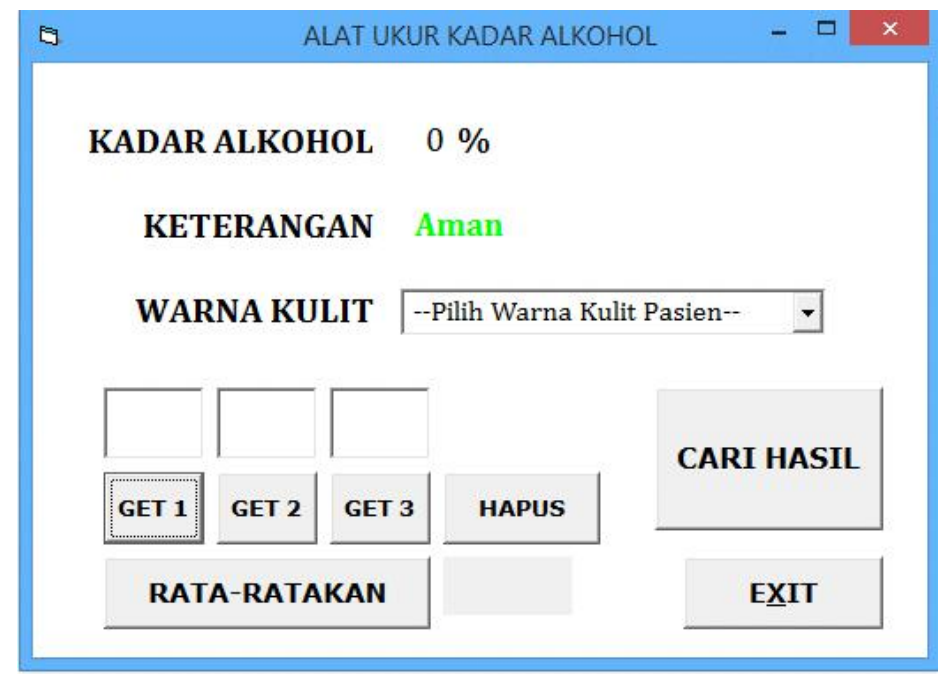

Gambar 3.4 Pengujian tampilan pada Label Kadar Alkohol dan Label Keterangan

Gambar 3.4 diatas adalah Form Utama pada alat ukur kadar alkohol yang dirancang mengikuti desain yang dibuat oleh penulis. Terdapat TextBox dan Label yang menampilkan angka dan keterangan pada Main Menu. ComboBox untuk memasukkan nilai variabel warna kulit pasien. Command Button Get untuk mengambil nilai variabel kadar alkohol melalui input berupa sensor MQ-3 yang diintegrasikan dengan Arduino UNO.

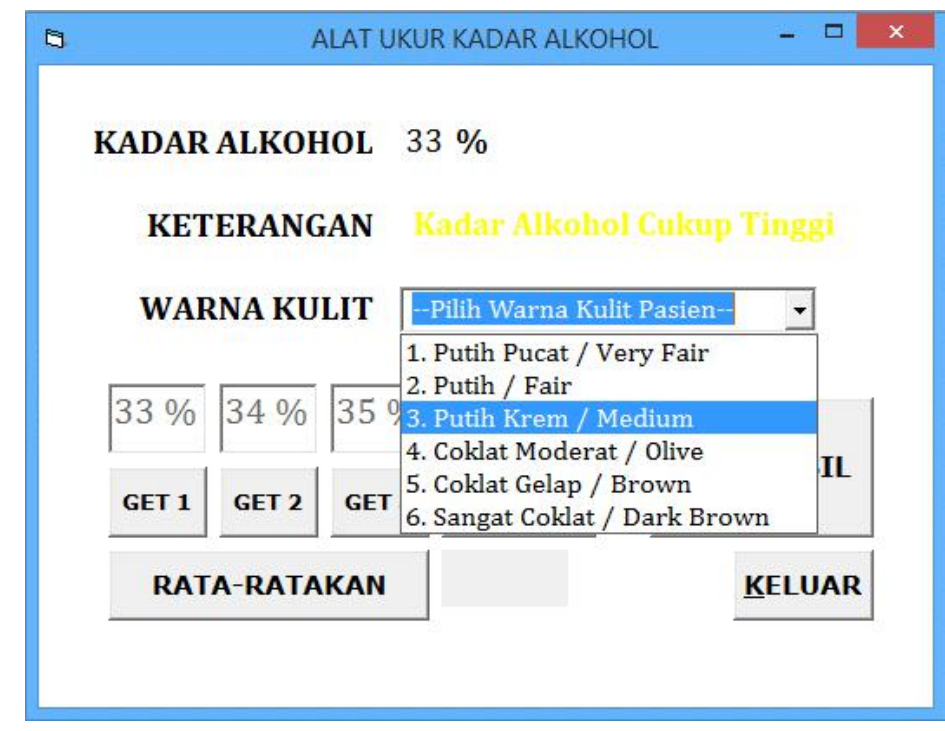

Gambar 3.5 Pengujian input nilai pada ComboBox Warna Kulit

Pada gambar 3.5 diatas, terdapat beberapa pilihan warna kulit. Masing-masing warna kulit memiliki nilainya masing-masing. Warna kulit yang penulis masukkan sebagai variabel warna kulit, yaitu : Putih Pucat, Putih, Putih Krem, Coklat Moderat, Coklat Gelap, dan Sangat Coklat. Nilai-nilai warna kulit tersebut ditulis sebagai berikut : 
Tabel 3.1 Jenis-Jenis Warna Kulit dan Nilai Warna Kulit

\begin{tabular}{|c|c|c|}
\hline No & Nama Warna Kulit & Nilai \\
\hline 1 & Putih Pucat / Very Fair & 30 \\
\hline 2 & Putih / Fair & 40 \\
\hline 3 & Putih Krem / Medium & 50 \\
\hline 4 & Coklat Moderat / Olive & 60 \\
\hline 5 & Coklat Gelap / Brown & 70 \\
\hline 6 & Sangat Coklat / Dark Brown & 80 \\
\hline
\end{tabular}

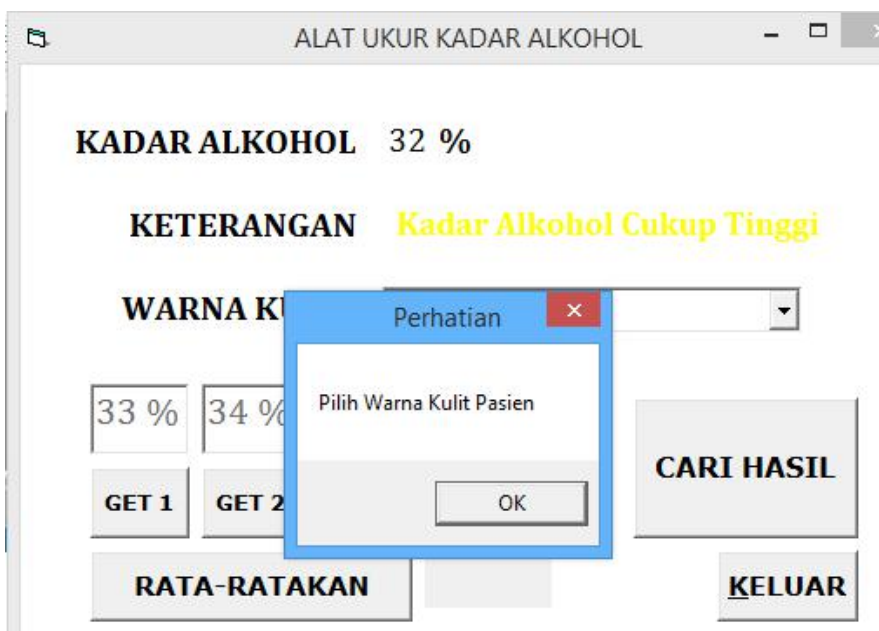

Gambar 3.6 Pengujian input nilai sembarang pada ComboBox Warna Kulit

Pada perancangan alat ukur ini, jika pengguna mengisi nilai warna kulit sembarangan atau mengisi nilai warna kulit tidak sesuai pilihan, maka akan keluar Message Box yang akan menuntun pengguna untuk tetap mengisi nilai Warna Kulit terlebih dahulu. Sehingga Combo Box warna kulit akan diisi sesuai nilainya. Jika tidak diisi dengan nilai yang seharusnya, maka akan muncul MessageBox "Pilih Warna Kulit Pasien". 


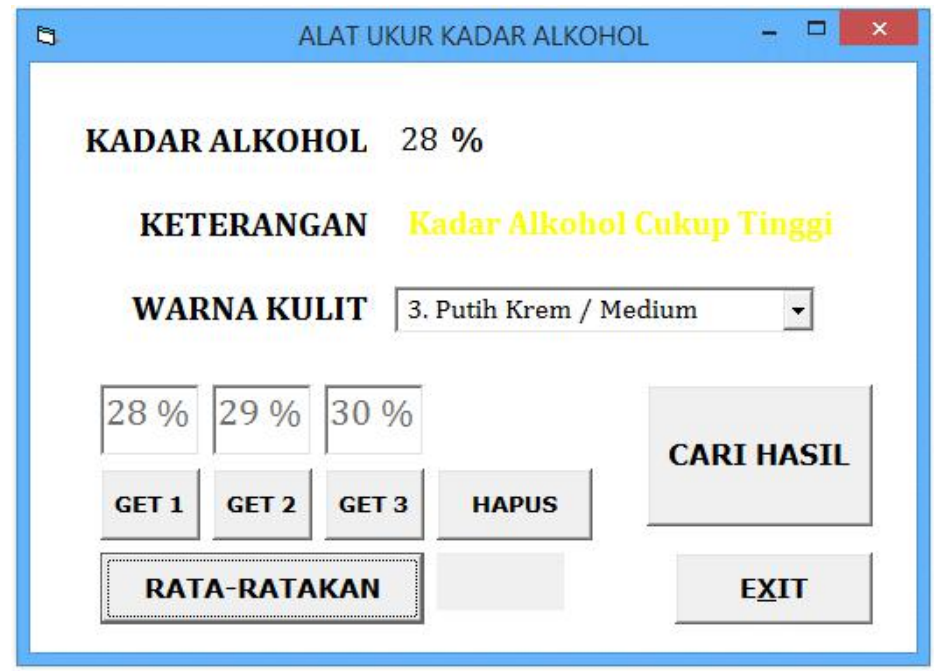

Gambar 3.7 Pengujian CommandButton Get1, Get2, Get3

Pada gambar 3.7 diatas, Command Button Get1, Get2, Get3 digunakan untuk mengambil nilai berupa persentase kadar alkohol melalui sensor MQ-3 yang di integrasikan dengan Arduino UNO. Nilai di kirim dari sensor MQ-3 melewati USB Cable, kemudian di proses dan di tampilkan di Label pada aplikasi. Command Button Get1, Get2, Get3 akan mengambil nilai kadar alkohol yang terus berubah-ubah.

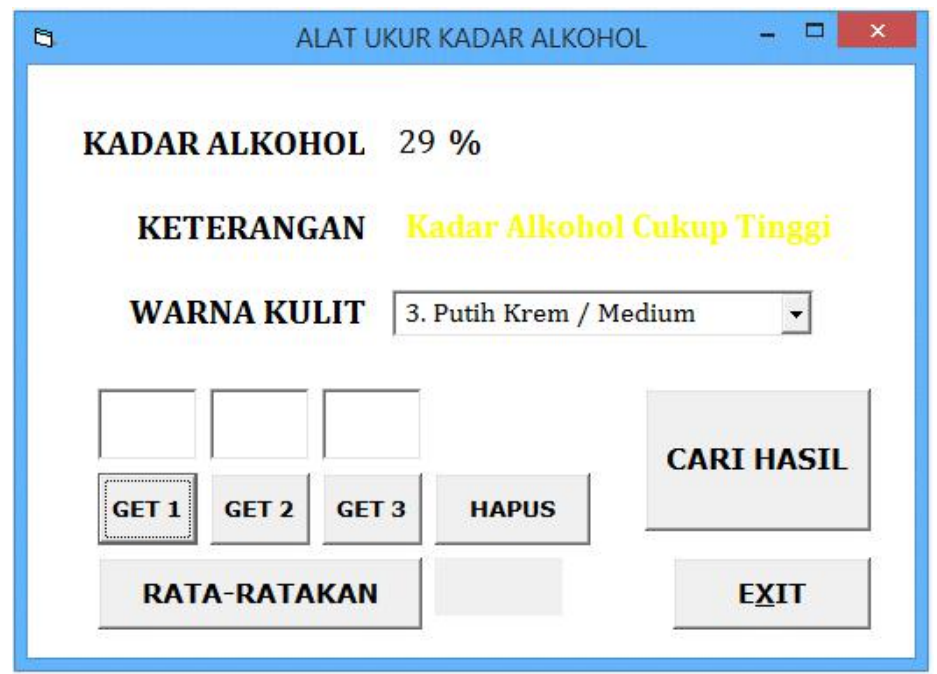

Gambar 3.8 Pengujian CommandButton Hapus

Pada Gambar 3.8 diatas, Command Button Hapus akan menghapus TextBox yang menampilkan nilai kadar alkohol saja. Command Button Hapus digunakan supaya pengguna dapat mengambil ulang nilai alkohol jika di inginkan. Setelah itu pengguna harus merataratakan 3 nilai kadar alkohol yang telah diambil dengan Command Button Rata-ratakan. 


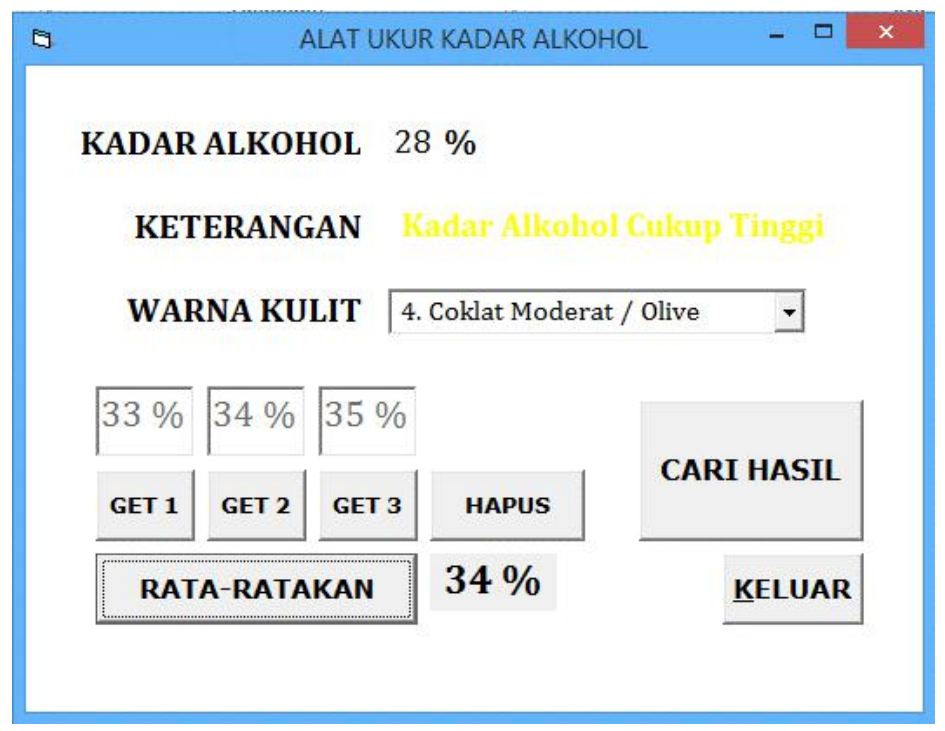

Gambar 4.33 Pengujian CommandButton Rata-Ratakan

Pada Gambar 3.9 diatas, CommandButton Rata-ratakan berfungsi dengan baik. CommandButton Rata-ratakan akan merata-ratakan 3 nilai yang telah di ambil. Kemudian nilainya akan di tampilkan pada Label. Pada pengujian yang sesuai dengan gambar diatas, pengguna mengambil nilai 33\%, 34\%, dan 35\%, dimana jika ditotalkan adalah 102. Kemudian nilai 102 akan dibagi oleh 3, hasilnya 34\%. Hasil dari rata-rata nilai kadar alkohol tersebut ditampilkan pada Label sesuai pada Gambar 3.9 diatas.

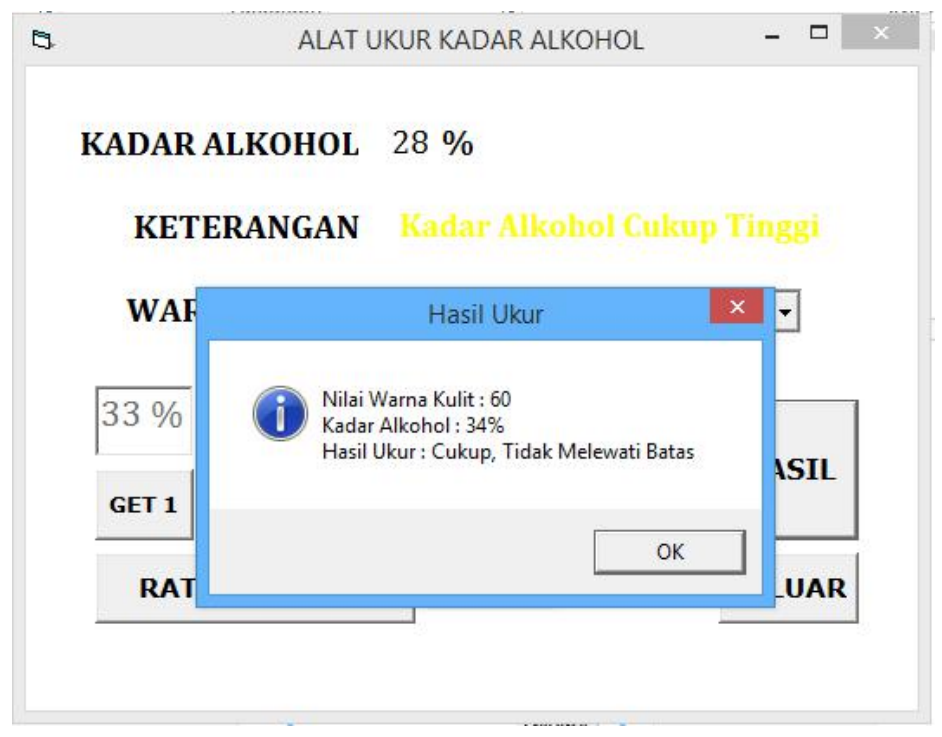

Gambar 3.10 Pengujian CommandButton Cari Hasil

Pada Gambar 3.10 diatas, CommandButton Cari Hasil akan menampilkan nilai Warna Kulit dan nilai Kadar Alkohol yang di ambil oleh pengguna. Pada CommandButton Cari Hasil juga akan menampilkan hasil dari perhitungan Logika Fuzzy. Nilai hasil Fuzzifikasi dan Defuzzifikasi tidak akan ditampilkan. Nilai akan di masukkan ke rentang nilai, apakah dengan 
hasil perhitungan nilai tersebut, kadar alkohol dan nilai warna kulit cocok untuk digunakan atau tidak. Pada gambar di atas dengan nilai warna kulit 60, yaitu Coklat Moderat dan kadar alkohol 34\% maka hasil perhitungan logika Fuzzy akan menunjukkan bahwa nilai tersebut masih masuk dalam rentang Cukup dan dapat digunakan untuk obat kompres pada obat tradisional ramuan patah tulang.

\subsection{Pengujian Jarak Sensor MQ-3}

Pada penulisan kali ini, penulis menggunakan pengujian jarak pada sensor MQ-3 untuk mengetahui efektivitas kinerja sensor. Pengujian jarak adalah pengujian yang harus dilakukan pada perancangan alat ukur kadar alkohol berbasis mikrokontroler. Harus dilakukan karena kita harus mengetahui terlebih dahulu apakah sensor MQ-3 bekerja maksimal atau tidak jika jarak sensor dan alkohol berbeda-beda. Berikut adalah tabel hasil pengujian jarak pada sensor MQ-3 dengan menggunakan alkohol 40\%.

Tabel 3.2 Hasil Pengujian Jarak Sensor MQ-3

\begin{tabular}{|c|c|c|}
\hline No & $\begin{array}{c}\text { Jarak Alkohol dari Sensor MQ-3 } \\
(\mathrm{cm})\end{array}$ & $\begin{array}{c}\text { Hasil Pengujian } \\
(\%)\end{array}$ \\
\hline 1 & $2 \mathrm{~cm}$ & $45 \%$ \\
\hline 2 & $3 \mathrm{~cm}$ & $43 \%$ \\
\hline 3 & $5 \mathrm{~cm}$ & $40 \%$ \\
\hline 4 & $7 \mathrm{~cm}$ & $37 \%$ \\
\hline 5 & $10 \mathrm{~cm}$ & $35 \%$ \\
\hline
\end{tabular}

Pada Tabel 3.2 diatas, pengujian menggunakan alkohol yang dituangkan kedalam gelas ukur yang biasa digunakan di laboratorium. Berdasarkan tabel 3.2 dapat kita lihat bahwa semakin jauh letak sensor dari alkohol yang akan di ukur, maka persentase kadar alkohol akan terus menurun. Ini menunjukkan bahwa sensor memiliki batas jarak maksimal, jika jarak sensor MQ-3 dan alkohol lebih dari $5 \mathrm{~cm}$ maka pengukuran kadar alkohol akan semakin tidak efektif. 


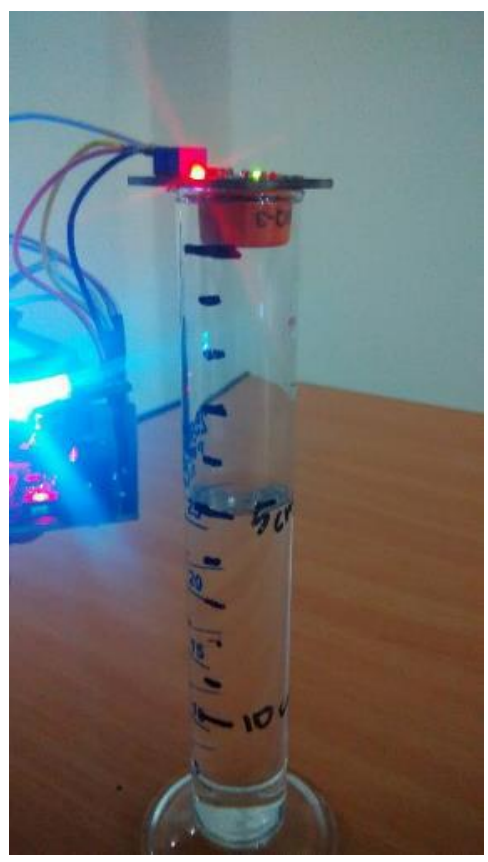

Gambar 3.11 Pengujian Jarak Pada Sensor MQ-3

Dapat kita lihat pada Gambar 3.11. Gelas ukur berisikan alkohol sebanyak 27ml. jarak sensor MQ-3 dengan cairan alkohol adalah $5 \mathrm{~cm}$. Pada pengujian diatas, dengan jarak $5 \mathrm{~cm}$ alkohol yang tertera pada LCD 16x2 adalah 40\%. Berarti dapat di simpulkan bahwa jarak $5 \mathrm{~cm}$ adalah jarak paling efektif untuk mengukur kadar alkohol yang dituangkan pada gelas ukur.

\section{KESIMPULAN}

Berdasarkan hasil perancangan yang telah dilakukan penulis pada perancangan alat ukur kadar alkohol, penulis menarik beberapa kesimpulan dan saran yang dapat dipertimbangkan dalam meningkatkan kinerja alat ukur untuk pengembangan yang lebih tinggi lagi kedepannya. Kesimpulan yang dapat diambil adalah sebagai berikut :

a. Alat ukur kadar alkohol berbasis mikrokontroler ini sudah dapat menampilkan persentase kadar alkohol dengan real time, menampilkan keterangan alkohol, menampilkan hasil perhitungan dengan fuzzy Tsukamoto, dan juga dapat memberikan saran apabila alkohol yang digunakan terlalu rendah atau terlalu tinggi.

b. Alat ukur kadar alkohol ini menggunakan mikrokontroler Arduino UNO, dimana inputnya ada 2, yaitu warna kulit dan kadar alkohol. Nilai warna kulit didapat dari nilai yang dipilih oleh pengguna aplikasi, sedangkan nilai kadar alkohol diperoleh dari nilai yang di baca pada sensor MQ-3 yang terpasang pada Arduino UNO.

c. Jika kadar alkohol lebih dari 25\%, maka di layar antarmuka akan memberikan keterangan "Kadar Alkohol Cukup Tinggi". Jika lebih tinggi dari 40\%, maka lampu LED merah akan menyala dan di layar antarmuka akan memberikan keterangan "Kadar Alkohol Terlalu Tinggi”. 


\section{SARAN}

Saran yang dapat diberikan penulis untuk meningkatkan kinerja dan efektivitas alat ukur alkohol ini, yaitu :

a. Tampilan aplikasi alat ukur ini masih sangat sederhana, sehingga masih butuh perkembangan lagi di bagian antarmuka untuk tampilan yang lebih menarik dan juga lebih user friendly sehingga pengguna dapat menggunakan aplikasi dengan lebih nyaman.

b. Alat ukur alkohol ini menggunakan mikrokontroler Arduino UNO dan sensor MQ-3 sebagai input. Untuk pengiriman data penulis menggunakan USB Cable, ini perlu ditingkatkan lagi dengan sistem wireless. Apakah dengan bluetooth maupun WLAN.

\section{DAFTAR PUSTAKA}

[1] Anthony, Pranata, 2002, Algoritma dan Pemrograman. J\&J Learning, Yogyakarta.

[2] Bodnar, George H., dan Hopwood, William S., 2004, Accounting Information Systems, Pearson Education, Inc., New Jersey.

[3] Hendriono, Dede, 2014, Mengenal Arduino UNO, http://www.hendriono.com/ blog/post/mengenal-arduino-uno, diakses 27 Oktober 2015.

[4] Jamilah, 2014, Pengenalan Bahasa C, http://jamilah.staff.gunadarma.ac.id/ Downloads/files/33355/pengenalan-c-sdcc.pdf, diakses pada 16 Oktober 2015.

[5] Kurniadi, Adi, 2000. Pemograman Microsoft Visual Basic 6.0. Penerbit Elex Media Komputindo, Jakarta.

[6] Kusrini. 2007, Konsep dan Aplikasi Sistem Pendukung Keputusan. ANDI, Yogyakarta

[7] Kusumo, Ario Suryo, 2000, Buku Latihan Microsoft Visual Basic 6.0. PT Elex Media Komputindo, Jakarta.

[8] Kusumadewi, Sri dan Purnomo Hari, 2004, Aplikasi Logika Fuzzy Untuk Pendukung Keputusan. Graha Ilmu, Yogyakarta.

[9] Nebath, Evert, David Pang, Janny O. W., 2014, Rancang Bangun Alat Pengukur Gas Berbahaya CO Dan CO2 di Lingkungan Industri, E-Journal Teknik Elektro dan Komputer 2014: 65-72.

[10] Ramli, Kalamullah, 2009, Arah Riset Sister Tertanam (Embedded System) dan Strategi Penguatan Industri Teknologi Informasi dan Komunikasi Nasional. Universitas Indonesia, Depok.

[11] Pressman, Roger S., 2002, Rekayasa Perangkat Lunak Pendekatan Praktisi (Buku Satu). ANDI Offset, Yogyakarta.

[12] Pressman, Roger S., 2012, Rekayasa Perangkat Lunak, jilid I. ANDI Offset, Yogyakarta.

[13] Rouf, Abdul, 2013, Pengujian Perangkat Lunak dengan Menggunakan Metode White Box dan Black Box. STMIK HIMSYA, Semarang.

[14] Soebhakti, Hendawan. 2006. Sistem Mikrokontroler. Politeknik Batam, Batam.

[16] Sasongko, Bagus Hari, 2012, Pemrograman Mikrokontroler dengan Bahasa C. ANDI, Yogyakarta.

[17] Soetam, Rizky, 2011, Konsep Dasar Rekayasa Perangkat Lunak. Prestasi, Jakarta.

[18] Suarga, 2006, Algoritma dan Pemrograman, ANDI, Yogyakarta.

[19] Sutedjo, Budi dan Michael A.N., 2000, Algoritma \& Teknik Pemrograman. ANDI, Yogyakarta.

[20] Widyanto dan Deni Erlansyah, 2014. Rancang Bangun Alat Deteksi Kebocoran Tabung Gas Elpiji Berbasis Arduino. Universitas Bina Darma, Palembang

[21] Winarto, Dwi, 2013, Golongan Alkohol, http://www.ilmukimia.org/2013/03/ golongan-alkohol.html, diakses 1 Oktober 2015. 